\title{
AIDS in Older People
}

$\mathrm{T}$ he diagnosis of acquired immunodeficiency syndrome (AIDS) has recently been found to decrease slightly for patients in many subgroups and age groups. A notable exception to this trend is the lack of decrease in AIDS in older people. $^{1-3}$

This development is accompanied by some special problems for older people, partly because of the greater stigma they attach to the diagnosis. In younger age groups, according to one study, only $89 \%$ of people with AIDS disclose this information to their physician. Disclosure of AIDS to the patient's dentist is even lower $(53 \%) .^{4}$ Many people choose to die of AIDS rather than have it identified officially, and more older than younger patients are likely to make this decision. ${ }^{5}$ As a result, older people can be expected to avoid the diagnosis of AIDS and may refuse to disclose it even if they are aware of it.

In older people, conditions that are comorbid with AIDS may cause nearly as much difficulty as the diagnosis itself. In particular, people who are homeless, nursing home patients, and persons in epidemic situations are often subject to an escalating threat of tuberculosis. ${ }^{6,7}$ Studies throughout the world have indicated increasing difficulty not only with tuberculosis but with resistant tuberculosis. ${ }^{8-10}$ In conjunction with this outbreak of tuberculosis, problems with compliance with medications for tuberculosis have increased. ${ }^{11}$ Although older people are among those who are diagnosed with tuberculosis, they also have special problems with some of the usual infections seen particularly in AIDS. It has been suggested that older adults have increased problems with relapse of Pneumocystis carinii pneumonia. ${ }^{12}$ AIDS may also lead to increased problems with certain cancers, in particular, cervical cancer, which is an increased problem in women with AIDS. ${ }^{13}$ Other coexisting illnesses complicated by AIDS include a wide variety of infections and cancers that have not been studied specifically in conjunction with AIDS. Because there is a wide variety of both infections and cancers among older people, there are likely many important entities that are worsened by AIDS and that will lead to increased mortality.

The spread of AIDS in older people is certain to lead to problems in regard to their health beliefs. These health presumptions have been particularly studied in women. Impressions about AIDS held by Latina women are sometimes accurate but are often inaccurate and very incomplete. ${ }^{14}$ The nursing literature also indicates that viewpoints about AIDS held by white women, especially low-income white women, are very inaccurate. ${ }^{15}$ Studies concerning AIDS in heterosexual women in Germany indicate an increasing problem, partly because of poor health practices and inaccurate beliefs about AIDS. ${ }^{1}$ Another study has indicated that it is very difficult to find infected women and to produce an accurate estimate of infection occurrence. ${ }^{16}$ Indications of the increase of AIDS in older American women have appeared for some time and were reviewed in an alert published in $1995^{3}$ and have also been reviewed by Tichy $^{2}$ and others.

\section{See also pp 153 and 249}

There are indications that treatment and care can be difficult for older people with AIDS. One of the reasons for this is that many have factors that tend to decrease their compliance with antiretroviral therapy. These include poverty, memory failure, and health beliefs that favor the use of nontraditional medications. Increasing compliance can be seen, however, when there is no history of intravenous drug use and if the older individual is not depressed. ${ }^{17}$ In addition to the factors associated with treatment compliance, which will probably vary greatly among groups of older people, it is difficult to care for people who wish to stay home with the complications of AIDS. Because homecare would seem especially likely to be chosen by older persons, homecare units or mobile units will be indicated to help with the problem of their care. ${ }^{18}$

The study by Chen et al. in this issue of the Journal ${ }^{19}$ is based on the Maryland AIDS Registry from 1981 to 1984. Certain outcomes noted in the paper are worthy of further mention. First, the proportion of whites with AIDS was higher in the older group than in the younger group in this Maryland population. This probably reflects the location of the patients and their economic status. Second, transfusion appears to be a less important source of AIDS than sexual transmission and drug abuse in this group aged 60 years or older. This change is also noted in some of the international data. ${ }^{1}$

There is at least one important caveat in this interpretation of AIDS in older people. ${ }^{19}$ Now that the entities "wasting syndrome" and HIV encephalopathy contribute to diagnosis, there may be some inflation of case numbers as a result of inclusion of patients who would not previously have met criteria. These new cases are often active people with histories of indiscretions rather than blood transfusion.

As AIDS becomes more common in older people, the issue of the feasibility of screening arises. Because it is so difficult to recognize AIDS encephalopathy among other dementia cases, should AIDS screening become a part of dementia tests? The answer to this is probably no, unless the patient's history points to some high risk. However, older people are rarely questioned about such matters and may refuse to discuss drug abuse or their sexual history.

Problems with health beliefs merit further study in the United States and increased educational programs, possibly with posters in senior centers, talks in senior centers, and other forms of education. The effectiveness of various campaigns that point out the risk of AIDS to older people should be evaluated. 
A tragic part of the increased development of AIDS in older people is their shorter survival time compared with the younger people. This greater mortality may reflect actual damage by the HIV virus itself, the comorbid conditions of AIDS, and difficulties in compliance with treatment and in the delivery of care. It may also reflect a different mix of opportunistic infections, increased severity of the tuberculosis problem, or a decreased choice of aggressive treatment by older people. Reasons for increased mortality of AIDS in older people certainly need further study. ${ }^{20,21}$

The letter by Thong and Tuazon, also published in this issue of the Journal, reflects some of the successes in therapy in the case of a woman with AIDS. ${ }^{22}$ It also reflects the need to maintain vigilance for cases of AIDS in older, heterosexual women.

Many of the questions regarding prevention of AIDS in older people require much further study. Studies should include work on health beliefs in different subgroups, people's willingness to be tested for HIV, the feasibility of preventive vaccine trials, the likelihood of self-disclosure, use of appropriate precautions, design of education, and development of improved communication between physicians and patients.

Margaret Terpenning, $M D$

Department of Veterans Affairs Medical Center University of Michigan, Ann Arbor, Michigan

\section{REFERENCES}

1. Elfriede S, Leopold B. Women and AIDS in Germany - Results of a fouryear pilot programme of the German Ministry of Health. Int Conf AIDS 1993;9:108.

2. Tichy AM, Talashek ML. Older women. Sexually transmitted diseases and acquired immunodeficiency syndrome. Nurs Clin North Am 1992;27:937949.

3. AIDS Alert. Providers not diagnosing HIV in older women. AIDS Alert 1995;10;77-79.

4. Perry SW, Moffatt M Jr., Card CA et al. Self-disclosure of HIV infection to dentists and physicians. J Am Dent Assoc 1993;124:51-54.
S. Stall S, Catania J. AIDS risk behaviors among late middle-aged and eiderly Americans. Arch Intern Med 1994; 1:54:57.

6. Malin AS, McAdam KP. Escalating threat from tuberculosis: The third epidemic. Thorax 1995; 50 (suppl 1):S37-42.

7. Stead WW, To T. The significance of the tuberculin skin test in elderly persons. Ann Intern Med 1987;107:837-842.

8. Rose N, Shang H, Pfyffer (iE. Tuberculosis therapy in canton Zurich 1991 1993: What are the causes for recurrence and therapy failure? Schweiz. Med Wochenschr 1996;126:2059-2067.

9. Elliott AM, Halwiindi B, Hayes RJ et al. The impact of human immunodeficiency virus on mortality of patients treated for tuberculosis in a cohort study in Zambia. Tran R Soc Trop Med Hyg 1995;89:78-82.

10. Pablos-Mendez A, Sterling TR, Frieden TR. The relationship between delayed or incomplete treatment and all-causc mortality in parients with ruberculosis. JAMA 1996;276:1223-1228.

11. Pablos-Mendez A, Knirsch CA, Barr RC; et al. Nonadherence in tuberculosis treatment: Predictors and consequences in New York City. Am J Med 1997;102:164-170.

12. Opravil $M$, Weber R, Ledergerber $B$ et al. Compliance and laboratory data predict relapse rate of Pneumocystis carinii pneumonia during prophylaxis with aerosol pentamidine. Klin Woshenschr 1990;68:397-402.

13. Lovejoy NC, Anastasi JK. Squamous cell cervical lesions in women with and without AIDS. Cancer Nurse 1994;17:294-307.

14. Flaskerud JH, Calvillo ER. Belicfs about AIDS, health, and illness among low-income Latina women. Res Nurs Health 1991;14:431-438.

15. Flaskerud JH, Thompson J. Beliefs about AIDS, health, and illness in lowincome white women. Nurs Res 1991;40:266-271.

16. Guinan ME. Finding HIV-infected women - The clinician's role. J Am Med Women's Assoc 1992;47:92-93.

17. Singh N, Squier $\mathrm{C}$, Sivek $\mathrm{C}$ ct al. Determinants of compliance with antiretroviral therapy in patients with human immunodeficiency virus: Prospective assessment with implications for enhancing compliance. AIDS Care 1996;8:261-269.

18. Luna M, Martinez. J, Navarro S et al. Importance of home attention and follow up to succeed in therapeutic compliance to clinical trials in Mexico City: Mobile Unit Int Conf AIDS 1994;10:21.3.

19. Chen HX, Ryan PA, Ferguson RP et al. Characteristics of acquired immunodeficiency syndrome in the elderly. J Am Geriatr Soc 1998:46:153-156.

20. Adler W, Nagel JF. Acquired immunodeficiency syndrome in the elderly. Drugs Aging 1994;4:410.

21. Rozance CP. HIV and AIDS in older adults. Infect Dis Clin I'ract 1996;5:193.

22. Thong PI., Tuazon CU. Human immunodeficiency virus (HIV) in the elderly: A case report (letter). J Am Geriatr Soc 1998;46:249-250. 